\title{
Evolutionary Studies of Cooperation
}

\section{Introduction to the Special Issue}

\author{
John Bock
}

Published online: 18 September 2009

(C) Springer Science + Business Media, LLC 2009

Keywords Cooperation $\cdot$ Evolutionary anthropology $\cdot$ Kin selection $\cdot$ Reciprocity

Viewing cooperation through an evolutionary lens moves us toward a focus on the individual as an actor in social, cultural, and ecological context. This focus has included emphasis on costs and benefits to the individual in various temporal frames, hypothesized universal personality characteristics, and cultural transmission and modeling. The articles in this special issue address all of these emphases using data from four small-scale societies. They were originally presented in a session organized by John Q. Patton, and sponsored by the Evolutionary Anthropology Society, at the 2006 meetings of the American Anthropological Association.

The articles by Collings, Meehan, and Alvard tackle a fundamental issue in the evolutionary analysis of cooperation: Whom does one help? Behavioral ecologists have traditionally identified two primary influences on the answer to this questionkin selection and reciprocity. Because fitness, in the evolutionary sense, is genetic representation in succeeding generations, helping one's genetic kin to survive and reproduce benefits the individual doing the helping in proportion to their shared genes. Formalized by W. D. Hamilton (1964), kin selection is a powerful force promoting cooperation and helping behavior. But not all helping behavior is between kin. Behavioral ecologists have recognized another avenue to helping-reciprocal altruism, where individuals assist unrelated individuals in exchange for a future payback. Both kin selection and reciprocal altruism have come under increasing

J. Bock $(\bowtie)$

Department of Anthropology, California State University, Fullerton, PO Box 6846,

Fullerton, CA 92834-6846, USA

e-mail: jbock@fullerton.edu 
scrutiny in recent years as being insufficient explanations for cooperation in certain social contexts, especially in larger-scale groups.

The factors influencing hunting returns and the principles underlying food sharing are key areas of interest among evolutionary anthropologists. Collings addresses both issues in relation to age and birth order among a group of Arctic hunters. He finds that hunting success is heavily age-dependent and that men's hunting ability apparently continues to improve into adulthood. Men born earlier in the birth order tend to be better hunters, perhaps because they are learning to hunt with younger, more vigorous fathers and/or because they have fewer sibling competitors for their fathers' or others' time. Collings also finds that among these Arctic hunters, parents received the highest proportion of shared meat from men born earlier in the birth order, and this meat was distributed to the men's younger siblings. For men born later in the birth order, siblings were the direct recipient of most shared meat. These results emphasize the importance of kinship in food sharing in this community.

Meehan examines allmothering among Aka foragers and Ngandu horticulturists. Much recent work in evolutionary anthropology has focused on the role of extramaternal support of offspring (Hawkes et al. 2000; Kaplan et al. 2000; Hrdy 2009). Among both the Aka and the Ngandu, allomaternal care is an important means of coping with work demands on the mother and the concomitant trade-off between labor and maternal care that women face in these societies. Among the Aka, allomaternal care compensates nearly completely for reductions in maternal investment resulting from mothers' work. Among the Ngandu, the nature of women's work and the demands on their time mean that the reduction in maternal investment due to work is never completely made up by allomaternal care. In addition to the variation in compensation based on differences in subsistence strategy, there is great flexibility in who provides allomaternal care depending on residence pattern. In matrilocal residence, maternal kin provide the bulk of care. In patrilocal residence, fathers (among the Aka) and siblings (among the Ngandu) provide the bulk of care.

Alvard applies sophisticated mathematical analysis to a classic anthropological case-Chagnon's original analysis of "The Ax Fight." Alvard's previous work with the Lamalera had called into question the universality of genetic kinship as an organizing principle for social cooperation. The titular axe fight occurred in 1971 in the Yanomamö community of Mishimishiböwei-teri and was captured on film by Tim Asch. Alvard uses the extensive visual record and Chagnon's detailed genealogy and field notes to analyze the event using matrix regression and multidimensional scaling. Alvard shows that genetic relatedness is a primary organizing principle in the fight, whereas lineage identity had no significant effect on individuals' choice of sides. Alvard concludes that the kin selection hypothesis is supported in this famous event at Mishimishiböwei-teri, and he uses the variation between results from his own research among the Lamalera and this analysis to critically evaluate the utility of both kin selection and reciprocity as explanations for cooperation across societies. Alvard lays out the case for examining alternative explanations for cooperative behavior, such as group augmentation and mutualism, based in evolutionary thinking.

Strong reciprocity, manifested as third-party punishment, has been hypothesized to be a universal characteristic of humans that allows for high-levels of cooperation 
(Fehr et al. 2002). Marlowe examines the prevalence of third-party punishment in economic games among Hadza foragers. Marlowe played three monetary-based games with more than 100 Hadza: the dictator, ultimatum, and third-party punishment games. Marlowe finds that Hadza players actively use second-party punishment - that is, rejecting offers perceived as short-changing them in the ultimatum game. When they have the opportunity to punish an individual exhibiting similar behavior to another, however, Hadza participants only rarely choose this option. Compared to other groups of people in a large cross-cultural sample, Hadza participants were among the least likely to engage in third-party punishment. Marlowe places this behavior in the context of a mobile small-scale society where egalitarianism is emphasized and mobility and fluid residence offer relatively easy solutions to conflict. He critically analyzes the role of scale in cooperative behavior, providing an insightful corollary to Alvard's analysis.

As a collection, these papers represent current thinking among evolutionary anthropologists on issues related to cooperation in human societies. Although all four studies use data collected in small-scaled societies, they have important implications for our understanding of how population size, density, and the scale of social institutions affect the variation in the way that people cooperate and organize themselves. These papers emphasize the importance of kinship in small-scale societies but contribute important ideas to understanding the effect of more complex and denser social organization, emphasizing our evolved capacity to respond to social, cultural, and ecological context.

\section{References}

Fehr, E., Fischbacher, U., \& Gachter, S. (2002). Strong reciprocity, human cooperation, and the enforcement of social norms. Human Nature, 13, 1-25.

Hamilton, W. D. (1964). Genetical evolution of social behaviour, parts I and II. Journal of Theoretical Biology, 7(1-16), 17-52.

Hawkes, K., O’Connell, J. F., Alvarez, H., \& Charnov, E. L. (2000). The grandmother hypothesis and human evolution. In L. Cronk, N. Chagnon \& W. Irons (Eds.), Adaptation and human behavior: An anthropological perspective (pp. 231-252). New York: Aldine de Gruyter.

Hrdy, S. B. (2009). Mothers and others: The evolutionary origins of mutual understanding. Cambridge: Harvard University Press.

Kaplan, H., Hill, K., Lancaster, J., \& Hurtado, A. M. (2000). A theory of human life history evolution: diet, intelligence, and longevity. Evolutionary Anthropology, 9, 156-185.

John Bock is the Associate Editor of Human Nature and is a professor of anthropology and coordinator of the Environmental Studies Program at Cal State Fullerton. His research interests lie in the development of children's ecological competency, the evolution of human life history, and the evolutionary analysis of sustainability. He is currently involved in a multi-year transdisciplinary project to develop a holistic anthropology of childhood, and with David Lancy and Suzanne Gaskins is co-editor of the forthcoming volume The Anthropology of Learning in Childhood (Lanham, MD: AltaMira Press, in press). 